話 題

\section{小型活性炭カラムにおける有機 ガス破過曲線の近似計算の検討}

\section{Study on Approximate Calculation of Organic Vapor Breakthrough Curve by Small Size Column of Activated Carbon}

\section{安彦泰進 ${ }^{1}$} 1 独立行政法人労働安全衛生総合研究所
環境計測管理研究グループ

Hironobu AвIKO ${ }^{1}$

${ }^{1}$ Work Environment Research Group, National Institute of Occupational Safety and Health, Japan

doi: 10.1539/sangyoeisei.wadai12002 キー ワード: Activated carbon, Breakthrough curve, Organic vapor, Respirator, Sampling tube, Wheeler-Jonas equation

\section{I. 緒 言}

有機ガス用の呼吸保護具吸収缶や作業環境測定用捕 集管には，その内部に吸着材として活性炭が封入され ている。これらの活性炭層の利用可能時間やガス吸着 容量 ${ }^{1-6)}$ は，材料層の入口のガス濃度に対する出口のガ ス濃度の時間変化を表した破過（はか）状態（Fig. 1) により，破過時間・破過濃度という定義によって多く 議論がなされている．活性炭層での有機ガス破過状態 は，これまでに産業衛生分野と理工学分野の双方で実 測による把握の努力が多く行われてきており，現在で はさまざまな破過デー夕を見ることができる。しかし， 後述するように破過状態に影響を与える要素はとても 多いことから，あらゆる破過状態を実測により把握す ることは依然として難しい。そのために以前より，活

2012 年 9 月 27 日受付 ; 2013 年 1 月 9 日受理

J-STAGE 早期公開日：2013 年 1 月 25 日

連絡先：安彦泰進 † 214-8585 神奈川県川崎市多摩区長尾 6-21-1 独立行政法人労働安全衛生総合研究所 環境計測管理 研究グループ.

Correspondence to: H. Abiko, Work Environment Research Group, National Institute of Occupational Safety and Health, Japan, 6-21-1 Nagao, Tama-ku, Kawasaki, Kanagawa 214-8585, Japan (e-mail: abiko-h@umin.ac.jp)
性炭層の利用における数式モデルによる破過状態の予 測に対する期待も存在している ${ }^{1-3)}$.

活性炭層での破過状態を簡明に表した代表的な数式 モデルとしては, 吸着速度論と確率論に基づいて導か れた Wheeler-Jonas 式 4-6) が現在知られている。同式は, 次のように表される (Fig. 2).

$t_{\mathrm{b}}=\frac{W_{\mathrm{e}} W}{C_{0} Q}-\frac{\rho_{\mathrm{B}} W_{\mathrm{e}}}{k_{0} C_{0}} \ln \left(\frac{C_{0}-C}{C}\right)=W_{\mathrm{e}}\left\{\frac{W}{C_{0} Q}-\frac{\rho_{\mathrm{B}}}{k_{0} C_{0}} \ln \left(\frac{C_{0}-C}{C}\right)\right\}$ (1)

$t_{\mathrm{b}}=$ 破過時間 [min]

$W_{\mathrm{e}}=$ 活性炭の単位重量あたりの有機ガス吸着容量 $[\mathrm{g} / \mathrm{g}]$

$W=$ 活性炭層の重量 $[\mathrm{g}]$

$C_{0}=$ 入口ガス濃度 $\left[\mathrm{g} / \mathrm{cm}^{3}\right]$

$Q=$ ガス流量 $\left[\mathrm{cm}^{3} / \mathrm{min}\right]$

$\rho_{\mathrm{B}}=$ 活性炭層のかさ密度 $\left[\mathrm{g} / \mathrm{cm}^{3}\right]$

$k_{0}=$ 吸着速度定数 $\left[\mathrm{min}^{-1}\right]$

$C=$ 破過濃度（出口ガス濃度） $\left[\mathrm{g} / \mathrm{cm}^{3}\right]$

同式は最初に報告がなされてから久しく5,6), 日本国 内でも過去に紹介がなされている ${ }^{3)}$. しかし，現在ま でにその内容の普及と具体的な応用の広がりは，特に 日本国内ではほとんど見られていない. 同式の問題と しては，活性炭層内でのガス吸着が均等な確率で発生 することを前提とした理論式である4-6) ことが挙げられ る.つまり, 活性炭は結晶性の物質ではなく, ひとつ ひとつの粒子も完全に均質ではないことから，この不

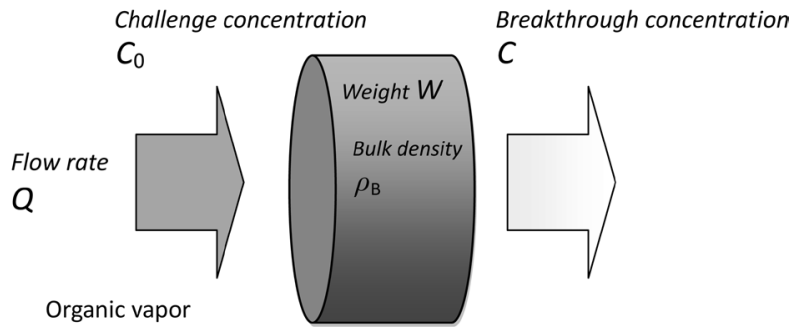

Activated carbon bed

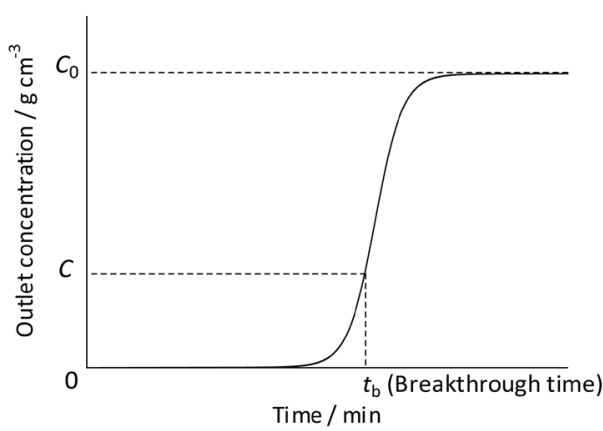

Fig. 1. Schematic overview of organic vapor breakthrough in activated carbon bed ${ }^{4}$. 


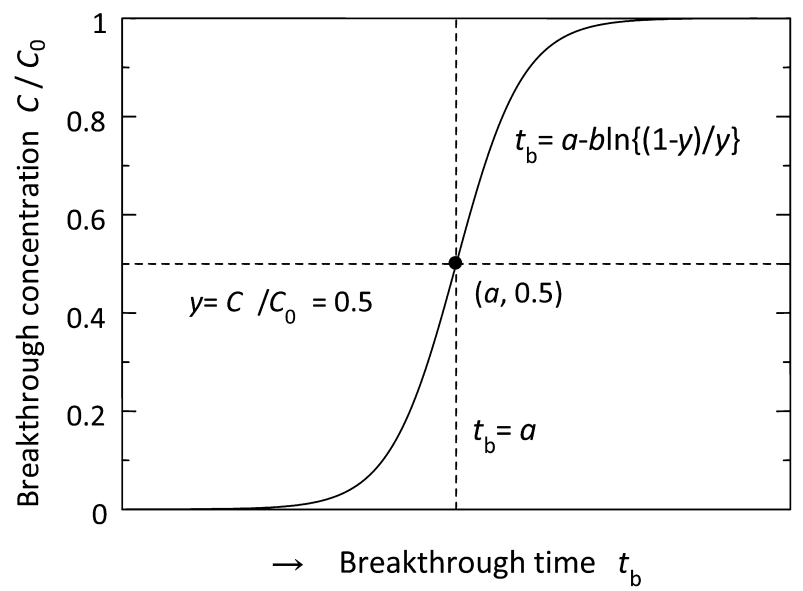

Fig. 2. Schematic overview of breakthrough curve calculated by Wheeler-Jonas equation ${ }^{4}$ ( $a, b=$ const.).

均一性が同式により表される曲線と, 実際の破過曲線 との不一致として影響する可能性も指摘される. また, 同式では実測データを元にして，上記のうち $W_{\mathrm{e}}, k_{0}$ の 2 つの值の決定が破過時間の推算のために必要である一 方, 測定条件から決定される定数が多くある. そのた め同式では，一定とする条件をどのように取るかによっ てさまざまな利用のかたちが考えられる，たとえば, 活性炭層の諸条件と有機ガスの濃度・流量に関する条 件を一定とした場合には, 有機ガスの種類による物質 依存性の議論や予測を同式により行うことができる. また, 活性炭層の諸条件と有機ガスの種類と流量を一 定とした場合には，入口・出口ガス濃度を変えた場合 の破過時間の変化の予測を行うことができる.さらに, 異なる活性炭製品や他の吸着材料での性能の比較を行
う際にも，同式の活用が考えられる.

ここで本稿では, 以上を踏まえて式 (1) を単独で簡易 な形に利用することを考え, 直径として 数 $\mathrm{cm}$ から 数 $\mathrm{mm}$ 程度となる小型の円筒状活性炭層での, 有機ガス破 過に適用した場合の有効性について検討した結果を以 下に示す.

\section{II. 対象と方法}

日本国内での小型の活性炭カラムを用いた有機ガス 破過測定の報告は，これまでに田中 7)，松村 8 ) らによ り多く行われている．今回はそれらのなかの測定デー 夕を利用して, 式 (1)による近似計算の検討を行った. それぞれの測定に使用された活性炭カラムの詳細と測 定条件は Table 1 に示すとおりである.

\section{III. 結果と考察}

Table 1 に示した田中らの測定では, 呼吸保護具吸収 缶に使用される大きさの活性炭層を対象としている. ここでの測定条件では, 破過濃度はそれぞれの入口ガ ス濃度に対して一定であり，いずれも $5 \mathrm{ppm}$ となって いる.よって, 式 (1) は下記のようにあらためた上で各 測定データでのフィッティングを行うことができる.

$$
t_{\mathrm{b}}=\frac{W_{\mathrm{e}} W}{C_{0} Q}-\frac{W_{\mathrm{e}} \rho_{\mathrm{B}}}{k_{0} C_{0}} \ln \left(\frac{1-\left(\frac{C}{C_{0}}\right)}{\left(\frac{C}{C_{0}}\right)}\right)
$$

各測定データでの式 (2)によるフィッティング（ここ

Table 1. Experimental conditions for organic vapor breakthrough measurements of small size columns of activated carbon by Tanaka et al. ${ }^{7)}$ and Matsumura ${ }^{8)}$

\begin{tabular}{|c|c|c|c|c|c|}
\hline Experimental data & Reference & Activated carbon product & $\begin{array}{l}\text { Raw material of } \\
\text { activated carbon }\end{array}$ & $\begin{array}{l}\text { Weight of activated } \\
\text { carbon bed }\end{array}$ & Bulk density \\
\hline A & 7 & $\begin{array}{l}\text { KOKEN KGC-8 } \\
\text { (Gas filter) }\end{array}$ & Unknown & $22.5 \mathrm{~g}$ & $\begin{array}{c}0.36 \mathrm{~g} / \mathrm{cm}^{3} \\
\text { (Inside diameter } 7.8 \mathrm{~cm} \text {, } \\
\text { Bed thickness } 1.3 \mathrm{~cm} \text { ) }\end{array}$ \\
\hline B & 8 & $\begin{array}{c}\text { Calgon Pittsburg } \\
\text { PCB } 12 \times 30 \\
\left(12-30 \mathrm{mesh}, 1,199 \mathrm{~m}^{2} / \mathrm{g}\right)\end{array}$ & Coconut shell & $0.1 \mathrm{~g}$ & $\begin{array}{c}\text { Unknown } \\
\text { (Inside diameter } 4 \mathrm{~mm} \text { ) }\end{array}$ \\
\hline Experimental data & Organic Vapor & $\begin{array}{l}\text { Breakthrough concentration } C \\
\text { / Challenge concentration } C_{0}\end{array}$ & Temperature & Relative humidity & Flow rate \\
\hline A & $\begin{array}{c}\text { Carbon tetrachloride } \\
\text { Ethyl acetate } \\
\text { Methyl acetate } \\
\text { Acetone } \\
\text { Dichloromethane }\end{array}$ & $\begin{array}{c}C=5 \mathrm{ppm} \\
C_{0}=100-900 \mathrm{ppm}\end{array}$ & $20^{\circ} \mathrm{C}$ & $50 \%$ & $30 \mathrm{l} / \mathrm{min}$ \\
\hline B & $\begin{array}{c}17 \text { types } \\
\text { described in Fig. } 4 .\end{array}$ & $C / C_{0}=0.01$ & $25^{\circ} \mathrm{C}$ & $80 \%$ & $0.1 \mathrm{l} / \mathrm{min}$ \\
\hline
\end{tabular}



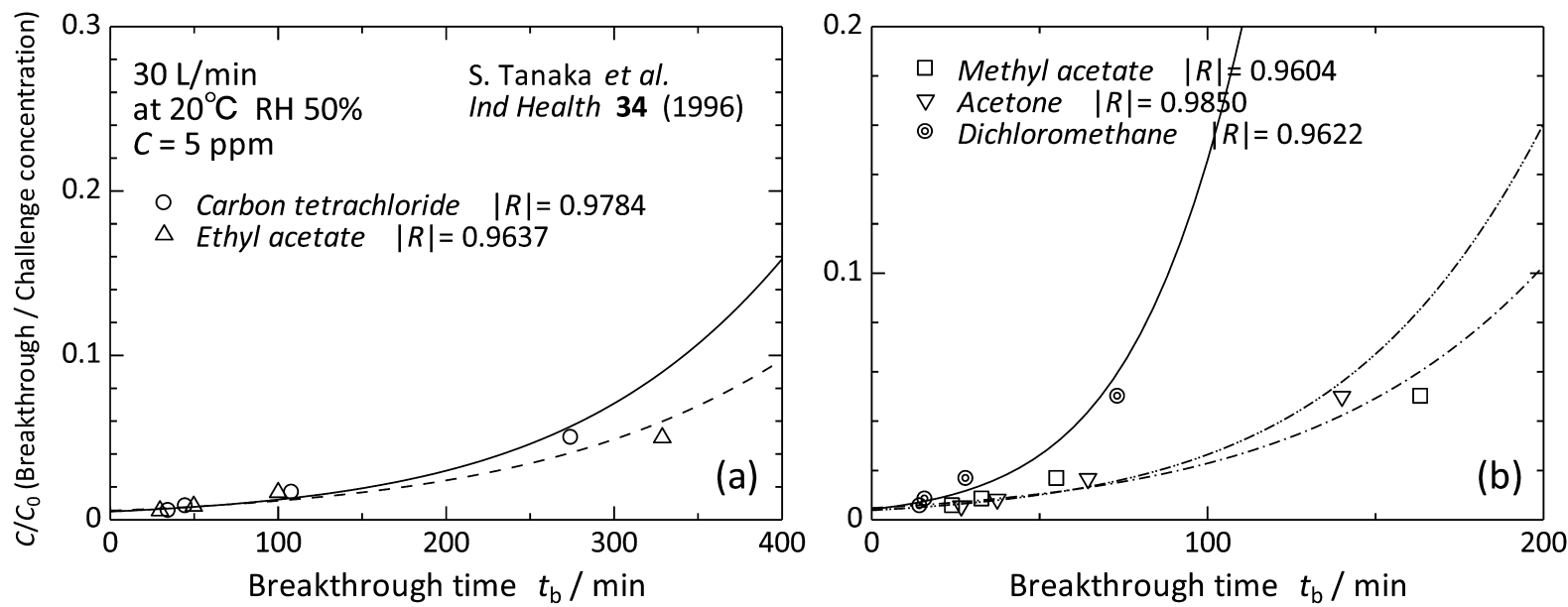

Fig. 3. Approximate calculation of breakthrough curves by Wheeler-Jonas equation ( $W_{\mathrm{e}}, k_{0}=$ const.) on experimental breakthrough data by Tanaka et $a l^{7}{ }^{7}$. $R=$ correlation coefficient.
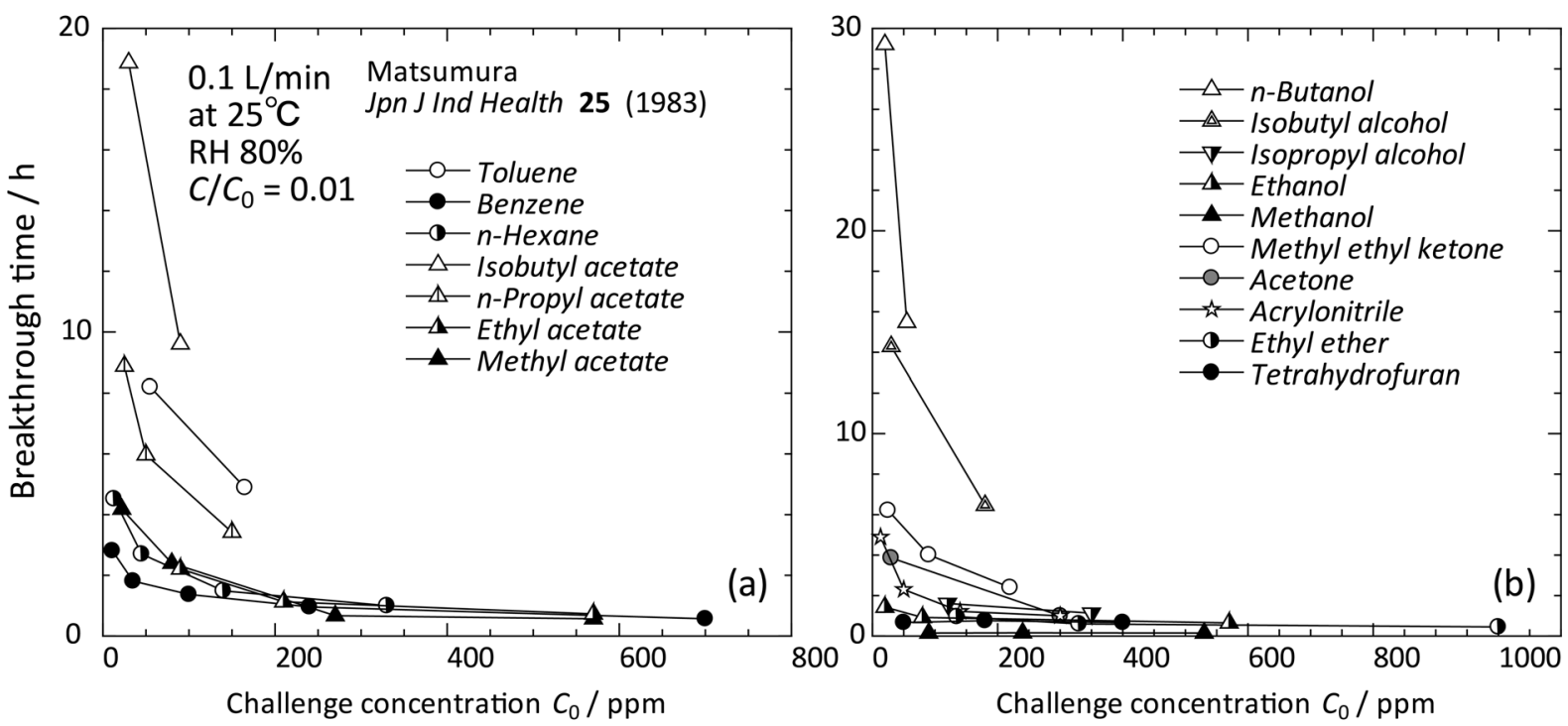

Fig. 4. Change of breakthrough time with challenge concentration in experimental breakthrough data by Matsumura ${ }^{8)}$.

では仮に $W_{\mathrm{e}}, k_{0}$ を入口ガス濃度によらず一定であると 見なした）に打いては，相関係数はいずれも抒拉よそ 良好な結果を示した（Fig. 3)。これより，田中らが用 いた大きさの水準の活性炭カラムならびに測定条件で は, さらに実測データで使用された以外の他の入口ガ 又濃度を適用した場合の破過時間の推算が, 式 (2) を用 いた近似曲線によって可能であると示唆される.

これに対し，Table 1 に示した松村の測定での活性炭 層は捕集管を模したものであり, 活性炭の使用重量は 0.1 $\mathrm{g}$ と小さい。また, 破過濃度はそれぞれの入口ガス濃度 に対しての $1 \%$, つまり $C / C_{0}=0.01$ との比率で決定さ れているため, 式(1) は式(3)のようにあらためられる.

$$
t_{\mathrm{b}}=W_{\mathrm{e}}\left\{\frac{W}{C_{0} Q}-\frac{\rho_{\mathrm{B}}}{k_{0} C_{0}} \ln \left(\frac{C_{0}-0.01 C_{0}}{0.01 C_{0}}\right)\right\}=\frac{W_{\mathrm{e}}}{C_{0}}\left(\frac{W}{Q}-\frac{\rho_{\mathrm{B}}}{k_{0}} \ln 99\right)
$$

ここで, 式 (1) での対数部分は定数 $(=\ln 99)$ となり,

同様に $W_{\mathrm{e}}, k_{0}$ が一定であると見なすと破過時間は入口 ガス濃度 $C_{0}$ に対して反比例に近い挙動を示すことが予 想される.しかし，各測定結果では多くの場合にその 傾向は見られず，入口ガス濃度の減少につれてさらな る破過時間の短縮の傾向が見受けられた (Fig. 4).

この原因については, Table 1 での比較からは田中ら の測定条件に対して松村の測定条件における相対湿度 が 80\% とかなり高いこと 9-11) や, 活性炭の使用重量が 小さいことが目を引くが，それらよりも $W_{\mathrm{e}} ， k_{0}$ に関す 

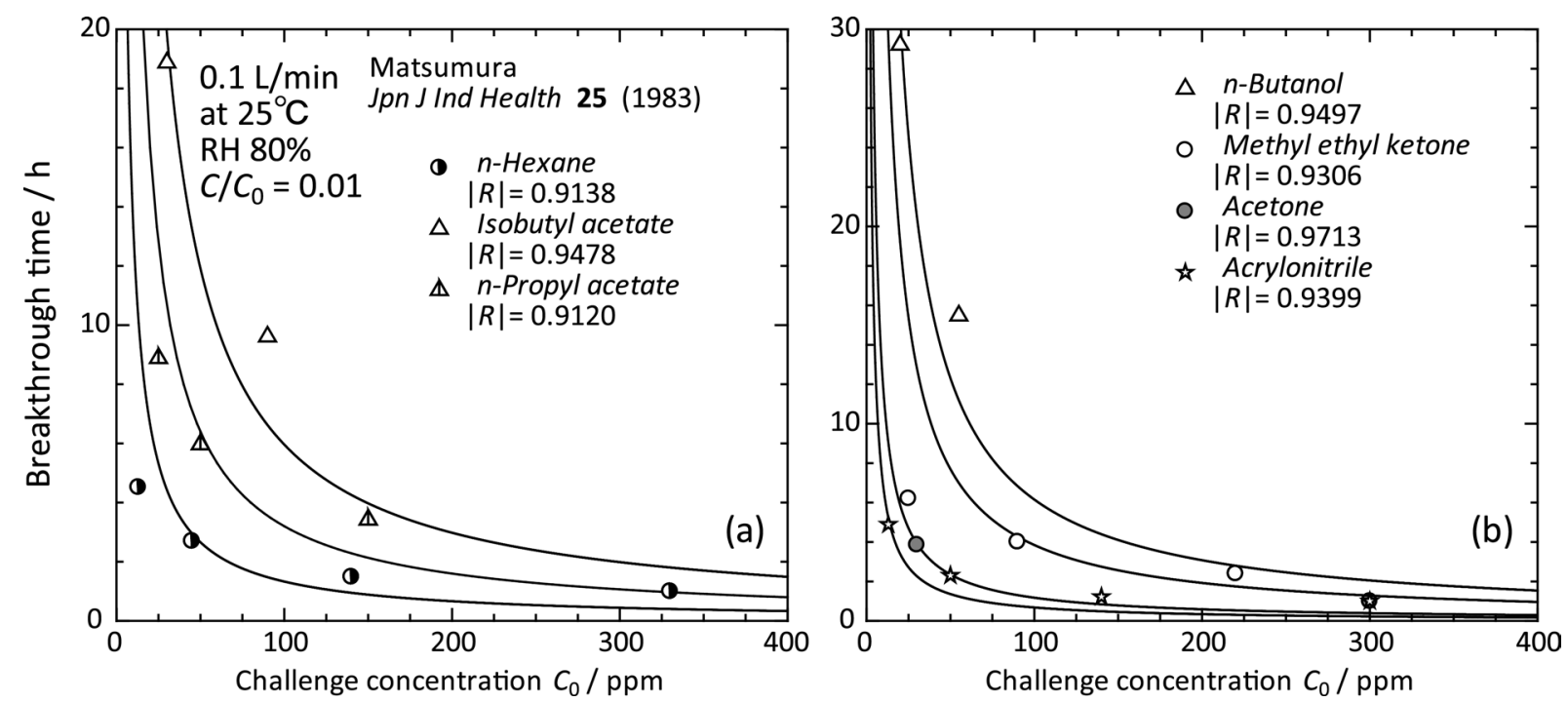

Fig. 5. Approximate calculation of breakthrough curves by Wheeler-Jonas equation $\left(W_{\mathrm{e}}, k_{0}=\right.$ const.) on some of experimental breakthrough data by Matsumura ${ }^{8}$.

る仮定が成り立たないことが影響していると考えられ る. 特に, 活性炭の単位重量あたりの有機ガス吸着容量 $W_{\mathrm{e}}$ は詳細には入口ガス濃度の值につれて変化する $\left.4,12,13\right)$ ものであり，松村の測定データではその影響がより明 瞭に現れていると考えられる。 そのため, $W_{\mathrm{e}}$ の決定に 関してはより詳しい取り扱いが望まれる。ただし，式 (3)によるフィッティングに関しては, 松村の測定デー 夕のなかで比較的長い破過時間を示す有機ガスのうち, 入口ガス濃度として $400 \mathrm{ppm}$ までのデー夕を対象とし た場合には，比較的見合った結果が得られた（Fig. 5)。 これより, 有機ガスの種類によっては, 入口ガス濃度 や他の条件も含めた変化が小さい範囲であれば 式 (1) の単独での利用による破過時間の予測が有効となる可 能性も示唆される。

以上のように，実際の適用には詳しく検討を要する 箇所も見られるものの，Wheeler-Jonas 式による活性炭 層での有機ガス破過状態の近似計算には, 呼吸保護具 吸収缶や排気設備・空気清浄機器に打ける活性炭フィ ルターなどの使用可能時間の予測や，それに基づく製 品の設計をはじめとして将来的な応用の可能性がある と見られる。産業衛生分野に拈いても，今後の同式の 利用の発展に向けた取り組みが期待される.

\section{文献}

1) 松村芳美. 活性炭層の有機物蒸気流に対する吸着特性. 安全工学 1966; 5: 120-3.

2) 松村芳美. 防毒マスク吸収缶の除毒特性. 労働衛生工学 $1980 ; 25-35$.
3) 保利 一. 吸着を利用した労働衛生管理用機器の特性と 課題. 労衝衛生工学 2007; 3-19.

4) 安彦泰進. Wheeler-Jonas 式による活性炭層のガス吸着の モデル化とその拡張を用いた破過時間の推算. 炭素 2011; 133-43.

5) Yoon YH, Nelson JH. Application of gas adsorption kinetics. I. A theoretical model for respirator cartridge service life. Am Ind Hyg Assoc J 1984; 45: 509-16. [Medline] [CrossRef]

6) Yoon YH, Nelson JH. Application of gas adsorption kineticsII. A theoretical model for respirator cartridge service life and its practical applications. Am Ind Hyg Assoc J 1984; 45: 517-24. [Medline] [CrossRef]

7) Tanaka S, Haneda M, Tanaka M, Kimura K, Seki Y. Breakthrough times for vapors of organic solvents with low boiling points in steady-state and pulsating flows on respirator cartridges. Ind Health 1996; 34: 125-31. [Medline] [CrossRef]

8) 松村芳美. 有機化合物蒸気捕集のための活性炭管の破過 時間. 産業医学 1983; 25: 512-3.

9) 安彦泰進. 呼吸保護具用活性炭製品の吸湿とその脱着の ヒステリシス。産衛誌 2010; 52: 216-8.

10) Abiko $\mathrm{H}$. Water vapor adsorption and desorption isotherms of activated carbon products used in Japanese gas respirators. TANSO 2011; 127-32.

11) Abiko H, Furuse M, Takano T. Quantitative evaluation of the effect of moisture contents of coconut shell activated carbon used for respirators on adsorption capacity for organic vapors. Ind Health 2010; 48: 52-60. [Medline] [CrossRef]

12) 安彦泰進. 市販木炭製品の細孔発達状態と有機ガス吸着 容量. 材料の科学と工学 2011; 48: 129-33.

13) Abiko H. Adsorption and desorption behavior of water and organic vapor of allophanic soil-templated porous carbon materials. J Ceram Soc Jpn 2012; 120: 603-8. [CrossRef] 